\title{
'Vaping' profiles and preferences: an online survey of electronic cigarette users
}

\author{
Lynne Dawkins ${ }^{1}$, John Turner, Amanda Roberts and Kirstie Soar \\ School of Psychology \\ University of East London \\ Water Lane \\ Stratford \\ London E15 4LZ
}

${ }^{1}$ Correponding author: tel.: 02082234421

e-mail: l.e.dawkins@uel.ac.uk

$\underline{\text { Running Head: Vaping profiles and preferences }}$

Word Count: 4,499

\begin{abstract}
Declaration of Interest
No funding was received for this study. The first author has a collaborative relationship with the Electronic Cigarette Company (TECC) and Totally Wicked E-Liquids (TWEL). TECC and TWEL reviewed and approved the content of the questionnaire and set up links from their web-sites to the host site at UEL.
\end{abstract}




\begin{abstract}
Aims to characterize e-cigarette use, users, and effects, in a sample of Electronic Cigarette Company (TECC) and Totally Wicked E-Liquid (TWEL) users. Design and Setting Online survey hosted at the University of East London with links from TECC/TWEL websites between September 2011 to May 2012. Measurements Online questionnaire. Participants 1347 respondents from 33 countries (72\% European), mean age 43 years, 70\% male, 96\% Causacian, $44 \%$ educated to degree level or above. Findings $74 \%$ reported not smoking for at least a few weeks since using the e-cigarette and 70\% reported reduced urge to smoke. $72 \%$ of participants used a 'tank' system, most commonly, the eGo-C (23\%). Mean duration of use was 10 months. Only $1 \%$ reported exclusive use of non-nicotine $(0 \mathrm{mg})$ containing liquid. E-cigarettes were generally considered to: be satisfying to use; elicit few side effects; be healthier than smoking; improve cough/breathing; and be associated with low levels of craving. Among ex-smokers, 'time to first vape' was significantly longer than 'time to first cigarette' $\left(\mathrm{t}_{1104}=11.16, \mathrm{P}<0.001\right)$ suggesting a lower level of dependence to e-cigarettes. Exsmokers reported significantly greater reduction in craving than current smokers $\left(\chi_{1}^{2}\right.$ =133.66, $\mathrm{P}<0.0007$ ) although few other differences emerged between these groups. Compared to males, females opted more for chocolate/sweet flavours $\left(\chi_{1}^{2}=16.16, P<0.001\right)$ and liked the e-cigarette because it resembles a cigarette $\left(\chi_{3}^{2}=42.65, P<0.001\right)$. Conclusions E-cigarettes tend to be used for smoking cessation but for a longer duration than NRT and were generally regarded as efficacious. Future research should focus on possible long-term health risks, abuse liability and cessation efficacy.
\end{abstract}




\section{Introduction}

Electronic cigarettes are battery-operated devices that deliver nicotine via inhaled vapour. Removable cartridges contain glycerol or propylene glycol, flavouring, and varying amounts of nicotine (including $0 \mathrm{mg}$ ). The nicotine solution is vaporized by an atomizer which is activated by 'drawing' on the device or pressing a button. 'Smoking' an electronic cigarette (e-cigarette) mimics the act of smoking and is often referred to as 'vaping'.

Since their introduction into the market in 2004 by the Ruyan Group (later re-named Dragonite) in China, e-cigarettes have gained popularity worldwide. The e-cigarette market is rapidly growing and highly fragmented with over 100 different brands. Its estimated revenue at retail in the US in May 2012 was over $\$ 250$ million and is expected to double by the end of 2012 [1,2].

Product sophistication has also improved during this time, arguably augmenting nicotine delivery. 'Tank' systems have been introduced which contain a fluid-filled reservoir rather than a saturated foam (traditional non-tank cartridges). Users can mix their own 'liquid' choosing from a range of flavours and strengths to refill cartridges. Some e-cigarettes (e.g. the Super \& Mini kits from TECC) are moving to 'cartomizers' in which the cartridge and atomizer are combined, allegedly resulting in a more efficient and tastier vape. Finally, since different voltages affect the vaping experience, variable voltage are a recent power control device that allow users to connect a range of atomizing devices and control the voltage that is applied to the atomizer.

In a recent, online population survey of 2649 adults in the US [3] 40.2\% of respondents had heard of e-cigarettes and $11.4 \%$ of smokers, $2 \%$ of ex-smokers and $0.5 \%$ of never-smokers had used them. In another survey of US individuals $(n=222)$ who had purchased an ecigarette, $67 \%$ of respondents reported that they had reduced their cigarette consumption and $49 \%$ had quit smoking completely (period of time unspecified) [4]. Nevertheless in the 
absence of data supporting these cessation claims, the World Health Organization (WHO) have banned therapeutic claims by manufacturers.

Although there is an absence of clinical trial data for e-cigarettes, three published empirical studies suggest they can provide moderate relief of craving and withdrawal symptoms $[5,6,7]$. Reports regarding delivery to the blood stream are inconsistent; three human studies reported very low blood nicotine levels in naive users $[5,6,8]$ whilst significant increases in salivary cotinine (a nicotine metabolite) [9] and blood nicotine levels [10] have been shown in regular users. This suggests the use of more sophisticated devices and/or experienced use is necessary for achieving effective nicotine delivery.

More still needs to be determined about the nature of e-cigarette use, namely: who uses them, their effectiveness for quitting/harm reduction, safety and addictive potential. The first survey of e-cigarette users ( $N=3587 ; 62 \%$ from US) has recently been published and has helped to answer some of these questions [11]. Sixty-one percent of the sample were men, $70 \%$ ex-smokers and $92 \%$ agreed that the e-cigarette had helped them to quit or reduce their smoking. Most (84\%) perceived the e-cigarette to be less toxic than smoking and reported using it to deal with tobacco craving (79\%) and withdrawal symptoms $(67 \%)$ or to quit smoking or avoid relapsing $(77 \%)$.

This study aims to add to the current knowledge of the nature of e-cigarette users, its use, and its effects. To ensure validity and generalizability, we used a more restricted sample of The Electronic Cigarette Company (TECC) and Totally Wicked E-Liquid (TWEL) users (the two most widely-used brands in the UK; [11]) recruited via their websites. We aimed to capture information regarding: the characteristics of e-cigarette users (e.g. age, gender, educational status and why they choose to use the e-cigarette); the nature of e-cigarette use (e.g. length and frequency of use, amount used, preferred flavours and devices, possible dependency and attempts to cut down); and positive (e.g. satisfaction, acceptability, effects on craving and smoking-behaviour) and negative effects (e.g. nausea, dizziness, throat/mouth irritation) of e-cigarette use. 


\section{Method}

The questionnaire was hosted on the University of East London (UEL) website with links from TECC and TWEL websites. Data were collected between September 2011 and May 2012. The survey was fully approved by the University of East London's ethics committee.

The questionnaire took approximately 15-20 minutes to complete and comprised 6 sections assessing:

A) Demographic information (age, gender, ethnicity, education and country) and smoking status: current smoker, ex-smoker or never-smokers (fewer than 20 cigarettes in your lifetime). Participants were directed to different sections depending on their smoking status.

C) Tobacco Smoking Information, including the Fagerström Test of Cigarette Dependence (FTCD; [12]), a six-item scale to assess cigarette dependence. Question 1 (commonly considered the strongest single-item predictor of dependence) asks: 'how soon after waking do you/did you smoke your first cigarette'? Participants indicate: 'within 5 minutes' (scored 3), 'between 6-30 minutes' (scored 2), '31-60 minutes' (scored 1) or 'after 60 minutes' (scored 0). Total scores are calculated on the 6-items and scores range from 0 (low dependence) to 10 (high dependence). An adapted version with wording in the past tense was used if participants indicated that they were ex-smokers. Ex-smokers were also asked 'how long has it been since you stopped smoking?' (less than 6 months, 6 months to 1 year, more than one year, more than 2 years).

D) Use of the e-cigarette, including length of use, product and cartridge type, strength and preferred flavours, amount used (in $\mathrm{ml}$ and puffs; where participants indicated a range, we took the top figure and refer to 'maximum daily use'), reasons for use (e.g. as a complete or partial alternative to smoking. Note: we did not specifically ask about use for quitting smoking as we did not want to prime respondents to endorse this response), dependence on the e-cigarette and attempts to cut down use.

E) Effects of the e-cigarette including satisfaction, hit, acceptability, taste, urge to smoke, impact on smoking behaviour and respiratory effects, all rated on a 4-point Likert Scale from 'not at all' to 'very much so'. 
F) Side-effects of the e-cigarette based on those previously used [10] rated on a 4-point Likert Scale from 'not at all' to 'all the time'

G) Other comments based on general patterns of use (to be analysed and presented elsewhere).

\section{Statistical analysis}

Results are presented for the whole sample (including 4 never-smokers who reported using the e-cigarette) and then for smoking group: ex-smokers $(\mathrm{N}=1123)$ vs. current smokers $(\mathrm{N}=$ 218) under each category heading. This smoking-group comparison was undertaken in response to a) the surprisingly high response rate from ex-smokers ( $N=1123,83 \%)$ and $b$ ) the observation that almost $100 \%$ of ex-smokers, compared with $50 \%$ of current smokers, stated that the e-cigarette had helped them to stop smoking which triggered an interest in exploring possible differences in user characteristics and patterns of use between ex and current smokers. Given that there is also increasing evidence that reinforcing aspects of smoking/nicotine may differ by gender $[7,13]$ and that vaping is more common among males [11], we also compared males $(N=897)$ vs. females $(N=390)$. Sample sizes vary by variable due to missing data. T-tests are used to compare means for continuous variables and frequency data are analysed using cross-tabulation with chi-square statistics. In some cases respondents could endorse more than one option (i.e. strength of liquid used, preferred flavour) whereas other variables were forced-choice (different response options indicated in tables). In the case of the former (more than one response permitted), separate chi-square analyses were conducted for each category; for the latter (forcedchoice options) overall chi-square tests are presented followed by pair-wise comparisons only where the overall effect is statistically significant. Given the multiple comparisons conducted here (70 for smokers vs. ex-smokers and 50 for males vs. females) we used a Bonferroni correction thus a $p$ value of 0.0007 was accepted as cut-off for statistical significance for smoker group comparisons and $p=0.001$ for gender comparisons 


\section{Results}

\section{Participant information}

Of the total 1376 responses, 27 were removed: 13 were blank; 10 were double entries, and 4 had considerable missing data. Of the remaining 1349 entries, 1123 (83\%) described themselves as ex-smokers, $218(16 \%)$ as current smokers and $6(4 \%)$ as never-smokers. Two never-smokers provided no data for the majority of e-cigarette questions indicating that they were not actually using the device so their entries were removed leaving a sample size of 1347.

Table 1 presents demographic information for the whole sample and for ex- versus current smokers. Participants responded from 33 different countries (72\% European): United Kingdom (23\%, $n=315)$; United States $(16 \%, n=210)$; Germany $(15 \%, n=205)$; France $(5 \%$, $n=61)$; Brazil (2\%, $n=22)$; Denmark (1\%, $n=12)$; Austria $(1 \%, n=9)$; Finland $(1 \%, n=9)$; Switzerland $(1 \%, n=8)$; others (36\%; $n<4$ [0.3\%] from each of the 24 other countries). There were no significant differences between ex and current smokers on any demographic variable or country of origin.

Compared with current smokers, ex-smokers as a group reported a higher level of cigarette dependence (FTCD total, See Table 1) and reported smoking sooner after waking (FTCD, question 1) but age of starting smoking did not differ by group. Thirty-eight percent of exsmokers reported that they had stopped smoking for more than one year; $19 \%$ had stopped for between 6 and 11 months and 43\% for less than 6 months.

\section{E-cigarette patterns of use}

Thirty-five percent $(n=448)$ of respondents stated that they had heard about the ecigarette from a personal contact, $41 \%(n=526)$ from the internet; $10 \%(n=134)$ via other media and $8 \%(n=100)$ saw it being used. Table 2 presents information on e-cigarette patterns of use for the whole sample and separately for ex- versus current-smokers. Twenty-three percent $(n=302)$ stated that they used their e-cigarette within 5 minutes of waking and $49 \%(n=645)$ within 6-30 minutes of waking (note: data presented in table are mean scores [between 0-3]). 
Duration of e-cigarette use was significantly longer in current than ex-smokers whilst exsmokers reported using the e-cigarette sooner after waking than did current smokers. Exsmokers also reported greater daily use (in $\mathrm{ml}$ and puffs) although this difference did not reach statistical significance at the adjusted $\alpha$ level. In ex-smokers, 'time until first cigarette' (based on retrospective reporting of former smoking habits) was significantly shorter than 'time until first vape' $\left(\mathrm{t}_{1104}=11.16, \mathrm{P}<0.0007\right)$.

Fifty-six percent $(n=744)$ of the whole sample answered 'yes' to the question 'do you use the e-cigarette in the same manner as cigarettes'. 589 (44\%) qualified their answer with comments: $6 \%(n=37)$ stated that they used it less and $29 \%(n=177)$ used it more. Of the latter, $5 \%(n=30)$ stated that they used it 'constantly' or 'chain vaped'; $13 . \%(n=79)$ used it more because vaping was permitted in places where smoking was not allowed; $17 \%(n=99)$ used the e-cigarette more frequently but took fewer puffs on each occasion. Two participants compared their use of the e-cigarette to 'snacking' and one to 'grazing'.

Unsurprisingly, $80 \%(n=1063)$ of stated products were TECC/TWEL products (see Table 2 for a breakdown of products used). There was a statistically significant overall group difference for product type. Follow up analyses of individual product type by group revealed that more ex-smokers than current smokers reported using the Tornado Tank eGo-C and custom made devices and more current smokers reported using the Titan 510 (non-tank) system although these differences fell short of the adjusted $\alpha$ level adopted here. Table 2 also provides frequencies and percentages for strengths and flavours used. The $18 \mathrm{mg}$ fluid was the most popular $(49 \%, n=663)$ and tobacco was the most popular flavour $(53 \%, n=664)$. There were no differences between current smokers and ex-smokers with respect to flavour preference.

\section{E-cigarette reasons for use and effects on tobacco consumption}

Survey respondents were asked why they started using the e-cigarette (see Table 3). Seventy-six percent (1027) of the whole sample reported wanting a 'complete alternative to smoking'. Twenty two percent stated 'other reasons' including: 'to quit smoking '( $7 \%, n=$ 
87), 'health reasons' $(6 \%, n=83)$, 'cost' $(3 \%, n=36)$ and 'to get round smoking restrictions' $(3 \%, \mathrm{n}=35)$. A higher proportion of ex-smokers than current smokers endorsed the 'complete alternative to smoking' item whilst a higher proportion of current smokers endorsed 'partial alternative to smoking'

In the whole sample, $74 \%(n=981)$ reported that they had not smoked for several weeks to several months since using the e-cigarette and a further $14 \%(n=184)$ reported that their cigarette consumption had decreased dramatically. Not surprisingly, a greater proportion of ex-smokers reported that they had not smoked for several weeks or months whilst significantly more current smokers reported that their tobacco consumption had decreased dramatically. E-cigarette use was also associated with a reduction in craving for tobacco cigarettes with $91 \%(n=1208)$ stating that their craving had 'decreased substantially'. Endorsement of this response was also significantly greater in ex than current smokers (see Table 3). Thirty percent ( $31 \%$ [ $n=339]$ of ex-smokers and $24 \%[n=24]$ of current smokers) stated that they had attempted to cut down their e-cigarette use. There were no group differences in terms of success in this endeavour (see Table 3).

\section{Positive effects of the e-cigarette}

Table 4 presents the percentage of the whole sample, and breakdown by smoking group, endorsing the 'not at all' and the 'very much so' responses relating to e-cigarette effects. Overall this sample reported positive effects of e-cigarette use, satisfaction levels were high and there was little evidence that e-cigarette use induced strong craving levels. A significantly higher proportion of ex-smokers reported that e-cigarette use: had helped them to stop or cut down smoking; was extremely satisfying; had reduced tobacco craving/urge to smoke; improved their cough and breathing, and felt healthier than smoking (see Table 4).

\section{Negative effects of the e-cigarette}

Very few adverse effects of e-cigarette use were reported (see Table 5). The most common was throat irritation, followed by mouth irritation. Of all the other side effects listed, less than $16 \%(n<202)$ reported experiencing any degree of effect and less than $3 \%(n<32)$ 
reported a high level of side effects. There were no significant differences with respect to reporting of adverse effects between ex- and current smokers.

\section{$\underline{\text { Gender differences }}$}

Female respondents were significantly older than males (mean 45.82 [11.52] vs $42.14 n$ [11.93]; $\left.\mathrm{t}_{1271}=-4.89, \mathrm{P}<0.001\right)$. There were no other significant gender differences for socio-demographic variables. Females rated themselves as significantly more dependent on cigarettes as measured by FTCD item one $\left(t_{1277}=-3.59 \mathrm{P}<0.001\right)$ and FTCD total score $\left(t_{1258}\right.$ $=-3.05,<0.01)$ although the latter was not statistically significant. In relation to e-cigarette use, there were no significant differences between males and females on 'time to first vape', duration of use, or estimated amount used. Although differences were not statistical significant fewer females reported using the Screwdriver $\left(\chi_{1}^{2}=8.21, p<0.01\right)$ or a tank system (of any sort; $\chi_{1}^{2}=6.80, p<0.01$ ) and more females reported using the Mini $\left(\chi_{1}^{2}=\right.$ $7.01, p<0.01)$ and Super $\left(\chi_{1}^{2}=7.78, p<0.01\right)$ devices. Females, however, were just as likely as males to report using custom made devices. There were no gender differences for strength of fluid used although males preferred tobacco flavour $\left(\chi_{1}^{2}=17.67, p<0.001\right)$ and more females reported using chocolate or other sweet flavours $\left(\chi_{1}^{2}=16.16, p<0.001\right)$. In response to the question, where did you hear about the e-cigarette, females were more likely to endorse the 'personal contact' response $\left(\chi^{2}{ }_{1}=14.24, p<0.001\right)$. Tabular data are not presented for gender; this is available on request.

There were no significant gender differences for any of the items relating to reasons for use, effects on tobacco consumption or craving, or attempt to cut down e-cigarette use. Females were however, significantly more likely to agree that: they 'liked the taste of the ecigarette $\left(\chi^{2}{ }_{3}=16.56, p<0.001\right)$; they 'liked the e-cigarette because it looks and feels like a cigarette' $\left(\chi_{3}^{2}=42.65, p<0.001\right)$; and 'the e-cigarette dramatically reduces my craving for nicotine' $\left(\chi_{3}^{2}=13.94, p<0.001\right)$. No gender differences emerged for reporting of side effects. 


\section{Discussion}

The present study aimed to characterize e-cigarette use, users, and effects, in a sample of visitors to TECC and TWEL websites. Survey respondents were predominantly ex-smokers who wanted a complete alternative to smoking. The majority of respondents reported that e-cigarette use (vaping) had dramatically reduced their craving for cigarettes and helped them to stop or substantially reduce their tobacco consumption. Very few respondents reported using non-nicotine $(0 \mathrm{mg})$ containing cartridges/liquid. E-cigarettes were generally considered to be: satisfying to use, associated with very few side effects, healthier than smoking, and responsible for improved cough and breathing. Compared to current smokers, significantly more ex-smokers reported that vaping dramatically reduced their craving for tobacco smoking and there was a trend for more ex-smokers to report using a tank or custom-made device. No smoking group differences were observed for adverse effects or strengths or flavours used. Females opted more for chocolate/sweet flavours whereas males preferred tobacco flavoured liquids and tank systems. Compared to tobacco smoking, vaping was associated with lower craving and longer time until first use in the morning suggesting a lower level of dependence to e-cigarettes than to smoking. Nevertheless, only a third of the sample reported that they had attempted to cut down their e-cigarette use with varying levels of success.

Although participants in the current sample represented 33 different countries $(72 \%$ European), respondents were predominantly Caucasian males. This gender bias is consistent with previous observations [11] that e-cigarettes appeal more to men than women. The mean age of the sample (43 years) and the low percentage of non-smoking respondents, also consistent with the previous survey [11], may either reflect the lower age limit (18 years) for participation in both surveys or indicate that e-cigarettes are not attracting large numbers of young adults to a recreational nicotine habit. Eighty-three percent of the current sample described themselves as ex-smokers, $97 \%$ of whom reported that the e-cigarette had helped them to stop smoking. Self-reported (retrospective) nicotine dependency from smoking (as assessed by the FTCD total score and question 1) was higher for ex-smokers than current smokers. This was an unexpected finding since one 
might expect ex-smokers to be less dependent and thus better able to quit but it may reflect the retrospective nature of responding in ex-smokers.

As participants responded to adverts via the TECC and TWEL webpages, unsurprisingly, eighty percent of the sample stated that they used TECC/TWEL products and $72 \%$ used a tank system. Ex-smokers were more likely than current smokers to use the Tornado Tank eGo-C or custom made devices. Although this difference fell short of the adjusted level of statistical significance, it raises the possibility that tank systems are more effective for quitting smoking; an area of research which merits further exploration. The average maximum daily amount used was $3.36 \mathrm{ml}$ of fluid and 236 puffs; higher figures than reported previously [11]. Many respondents provided further details about their e-cigarette use which generally indicated that e-cigarettes are used more frequently throughout the day than cigarette smoking. This may reflect the fact that vaping is permitted in places were cigarette smoking is banned and/or that more puffs are required to achieve adequate blood nicotine levels [6].

Only $1 \%$ of the sample reported exclusive use of non-nicotine $(0 \mathrm{mg})$. Contrary to the finding that use of the 0mg e-cigarette in naïve users can reduce craving and withdrawal symptoms [7], these findings indicate that the nicotine content is an important constituent for regular users. This may be because more experienced users are better able to detect the effects of nicotine, and/or that the sensorimotor effects of non-nicotine containing e-cigarettes on withdrawal and craving are only short-lived. Alternatively, user expectations about the importance of nicotine may lead to greater use of nicotine-containing fluid. The most popular concentration of nicotine was $18 \mathrm{mg}$ and tobacco was the most popular flavour, consistent with the previous report [11].

Seventy four percent of the sample reported that they had not smoked for at least several weeks since using the e-cigarette and $57 \%$ reported that they had not smoked for several months. Thus, respondents seem to be using the e-cigarette as a quit smoking tool with high self-reported success rates. Nevertheless, whether e-cigarette use itself is discontinued is unclear; participants in our sample reported using the e-cigarette for an 
average of 10 months, much longer than the average duration of use reported previously ( 5 months [11]). This may reflect the recency of the present survey thus allowing respondents a longer time to vape, or it might reflect our sampling method; advertisements on TECC and TWEL websites would mean that only current e-cigarette users would have known about the study. Either way, 10 months is much longer than the recommended use of NRT (12 week [14]) suggesting that people may be using e-cigarettes as a longer-term replacement of the smoking habit rather than as a means of quitting nicotine intake completely.

This raises the question that e-cigarettes themselves could be addictive. Our findings concur with a recent report suggesting that e-cigarettes have a lower abuse potential than tobacco smoking [15]. Only $18 \%$ agreed that craving for e-cigarettes was as strong as craving for tobacco and ex-smokers indicated that time to first vape was longer than time until first cigarette. Notwithstanding that reports about former tobacco use may be subject to distortion given the retrospective nature of responding, these findings suggest a lower dependency on e-cigarettes compared to tobacco smoking. Nevertheless, only one-third of our sample reported that they had tried to cut down their e-cigarette use. This may reflect the nature of the sample, a general reluctance or malaise among the vaping community to stop using, or an inability or difficulty to do so. Of those attempting to cut down, only $12 \%$ reported that they had been 'very' or 'extremely' successful. Abuse liability of the ecigarette and effects of long-term use on health are two under-explored areas which clearly merit further attention.

The majority of the sample thought that e-cigarettes were healthier than tobacco smoking (81\%) and reported an improvement in cough and breathing (70\%). E-cigarettes were generally rated to be satisfying to use, associated with a dramatic reduction in tobacco craving and almost half of the sample agreed that the 'hit' was comparable to that of tobacco smoking. Very few side effects were endorsed (although negative effects would be the variable least likely to score highly amongst this cohort and would be better explored in a randomised controlled trial). Ex-smokers reported a greater benefit to their breathing, a stronger 'hit' and a greater reduction of craving from e-cigarette use than current smokers. There was also less reporting of aching jaws and throat irritation among ex-smokers. It is 
unclear whether these effects reflect differences between ex and current smokers in product choice which contributed to greater success in quitting smoking in the former, or whether quitting itself led to stronger perceived positive effects of e-cigarette use. Whilst an exploration of predictors of cessation success using the e-cigarette was beyond the scope of this paper, it would be interesting to explore such differences in a controlled study using regression analysis and confirmation of abstinence status.

Smoking status (ex vs. current) did not differ by gender, nor were there any gender differences on effects of e-cigarette use on tobacco smoking, manner of e-cigarette use, duration of use or amount used. Predictable flavour and product choice differences emerged with a female preference for chocolate and sweet flavours and a preference trend for Super and Mini products which resemble cigarettes. Indeed significantly more females than males endorsed the items 'I like the e-cigarette because it looks and feels like a cigarette' and 'I like the taste of the e-cigarette'. Although females did not opt for higher strength fluid, they were more likely to agree that the e-cigarette reduced their cigarette cravings. These observations resonate with the findings that, relative to males, females are less sensitive to the interoceptive effects of nicotine [16] and more responsive to nonnicotine, sensorimotor aspects of smoking $[7,13,17]$.

There are several limitations of this study, notably, the self-selected sample of TECC and TWEL users who responded to a link to the survey from the TECC/TWEL websites and whose smoking status and responses cannot be validated. Such respondents are likely to be current users with positive biases towards the e-cigarette, thus it is likely that unsatisfied users and ex-users are under-represented in this sample. There is also scope for 'gaming' here by individuals or organisations who might have a vested interest in promoting the beneficial effects of TECC/TWEL products or e-cigarettes in general against the backdrop of regulatory uncertainty and possible withdrawal of these products from the market $[18,19]$. This is particularly relevant to the current survey which was accessed by users of two leading UK e-cigarette retailer's websites whereas participants in the previous survey [11] were sampled from e-cigarette discussion forums and more 'neutral' stop-smoking sites. Nevertheless, reports regarding reasons for use, nature of use and positive and negative 
effects were similar across studies. Some of the questions used here (i.e. those relating to former tobacco smoking habits) required retrospective reporting. This is often subject to bias/distortion which makes comparisons between former smoking habits and current vaping less reliable. Overall then, while this study provides further insight into the nature of e-cigarette use, it is likely that these data over-estimate the efficacy of the e-cigarette, thus findings should be interpreted with caution.

Although these potential biases should be borne in mind, taken together, the results of this, and previous studies $[4,11]$ suggest that e-cigarette users who respond to online surveys vape as a complete or partial alternative to smoking. There was little evidence for dual use (smokers continuing to smoke at previous levels and adding nicotine via e-cigarette) or addictive potential in this sample. Although absolute safety and product quality should be more thoroughly evaluated, the implications of these findings for policy-makers, regulators and health-care providers are clear: prohibiting or discouraging the use of e-cigarettes could be detrimental to public health if smokers are deprived of a highly endorsed and welltolerated method of smoking cessation.

To conclude, the findings from this survey of self-selected, largely European TECC and TWEL e-cigarette users are broadly consistent with a previous large-scale survey [11] and suggest that e-cigarettes are used largely by smokers to quit smoking, with a high degree of success. Results reveal that e-cigarettes: were satisfying to use, reduced cravings for tobacco cigarettes, were associated with very few immediate side effects and tended to be used for a longer duration than NRT. Future research should concentrate on possible health risks associated with long-term use, efficacy for smoking cessation (with possible brand/product differences) and abuse potential. 


\section{References}

1. Herzog, B., Metrano, B., Gerberi, J. Tobacco Talk Survey: E-Cigarettes a promising opportunity. Equity Research, Wells Fargo Securities 2012. Available at: http://www.stevevape.com/wp-content/uploads/2012/05/E-Cigs-A-PromisingOpportunity.pdf (accessed 25 September 2012)

2. Modi, N., Schmid, B., Miller, R. US Tobacco. Clearing the smoke on e-cigarettes. UBS Investment Research (2012). Available at: http://www.stevevape.com/wpcontent/uploads/2012/05/Clearing-the-Smoke-on-E-Cigarettes.pdf (accessed 25 September, 2012)

3. Pearson, J. L., Richardson, A., Niaura, R. S., Vallone, D. M., Abrams, D. B. E-cigarette awareness, use and harm perceptions in US adults. American Journal of Public Health 2012; 102: 1758-66.

4. Siegel, M. B., Tanwar, K. L., Wood, K. S. Electronic cigarettes as a smoking-cessation tool: results from an online survey. American Journal of Preventative Medicine 2011; 40: 472-5.

5. Bullen, C., McRobbie, H., Thornley, S., Glover, M., Lin, R., Langesen, M. Effect of an electronic nicotine delivery device (e cigarette) on desire to smoke and withdrawal, user preferences and nicotine delivery: randomised cross-over trial. Tobacco Control 2010; 19: 98-103.

6. Vansickel, A. R., Cobb, C. O., Weaver, M. F., Eissenberg, T. E. A clinical laboratory model for evaluating the acute effects of electronic 'cigarettes': Nicotine delivery profile and cardiovascular and subjective effects. Cancer Epidemiology, Biomarkers \& Prevention 2010; 19: 1945-1953.

7. Dawkins, L., Turner, J., Hasna, S., Soar, K. The electronic-cigarette: Effects on desire to smoke, mood and cognition. Addictive Behaviour 2012; 37: 970-973.

8. Eissenberg, T. Electronic nicotine delivery devices: ineffective nicotine delivery and craving suppression after acute administration. Tobacco Control 2010; 19: 87-88.

9. Etter, J. F., Bullen, C. Saliva cotinine levels in users of electronic cigarettes. European Respiratory Journal 2011; 38: 1219-20. 
10. Vansickel, A. R., Eissenberg, T. Electronic cigarettes: effective nicotine delivery after acute administration. Nicotine and Tobacco Research 2012; Advance access Feb 6; doi: $10.1093 / n t r / n t r 316$

11. Etter, J. F., Bullen, C. Electronic cigarette: users profile, utilization, satisfaction and perceived efficacy. Addiction 2011; 106: 2017-28.

12. Fagerström, K. O. Determinants of tobacco use and renaming the FTND to the Fagerström Test for Cigarette Dependence. Nicotine and Tobacco Research 2012; 14: $75-8$.

13. Perkins, K. A., Donny, E., Caggiula, A. R. Sex differences in nicotine effects and selfadministration: review of human and animal evidence. Nicotine and Tobacco Research 1999; 1: 301-15.

14. McEwen, A., Hajek, P., McRobbie, H., West, R. Manual of Smoking Cessation. Oxford: Blackwell Publishing; Addiction Press 2006.

15. Vansickel, A. R., Weaver, M. F., Eissenberg, T. Clinical laboratory assessment of the abuse liability of an electronic cigarette. Addiction 2012; 107: 1493-1500.

16. Perkins, K. A. Nicotine discrimination in men and women. Pharmacology, Biochemistry, and Behavior 1999; 64: 295-9.

17. Barrett, S. P. \& Darredeau, C. The acute effects of nicotine on the subjective and behavioural responses to denicotinized tobacco in dependent male and female smokers. Behavioral Pharmacology 2012; 23: 221-7.

18. Deyton, L. R., Woodcock, J. Regulation of e-cigarettes and other tobacco products. http://www.fda.gov/NewsEvents/PublicHealthFocus/ucm252360.htm 25 April 2011; (accessed 23 November 2012).

19. World Health Organisation (WHO). WHO study group on tobacco product regulation. Report on the Scientific Basis of Tobacco Product Regulation: Third Report of a WHO study group. WHO Technical Report Series. Geneva: WHO; 2009. 
TABLES

Table 1: Participant demographic and smoking-related information

\begin{tabular}{|c|c|c|c|c|c|c|c|c|}
\hline & \multicolumn{2}{|c|}{ Whole Sample } & \multicolumn{2}{|c|}{ Ex-smokers } & \multicolumn{2}{|c|}{ Current smokers } & \multirow[t]{2}{*}{$\mathbf{P}$} & \multirow{2}{*}{$\begin{array}{c}\text { Test } \\
\text { statistic }\end{array}$} \\
\hline & $\mathbf{N}$ & Mean (SD) & $\mathbf{N}$ & Mean (SD) & $\mathbf{N}$ & Mean (SD) & & \\
\hline Age (years) & 1302 & 43.39 (11.99) & 1084 & $43.34(11.76)$ & 212 & $43.54(13.10)$ & 0.84 & $t=-0.2$ \\
\hline Age started smoking & 1338 & $15.68(3.66)$ & 1121 & $15.6(3.63)$ & 218 & $16.13(3.78)$ & 0.047 & $t=-1.99$ \\
\hline FTCD & 1317 & $5.99(2.41)$ & 1107 & $6.20(2.30)$ & 210 & $4.93(2.66)$ & $<0.0007$ & $t=6.45$ \\
\hline $\begin{array}{l}\text { FTCD Q1: How soon after } \\
\text { waking do/did you smoke } \\
\text { cigarettes? }\end{array}$ & 1338 & $2.11(0.91)$ & 1121 & $2.17(0.87)$ & 217 & $1.79(1.04)$ & $<0.0007$ & $t=4.97$ \\
\hline & $\mathbf{N}$ & $\%$ & $\mathbf{N}$ & $\%$ & $\mathbf{N}$ & $\%$ & & \\
\hline Gender: & 1287 & & & & & & 0.78 & $x^{2}=0.078$ \\
\hline Male & 897 & 70 & 749 & 70 & 144 & 69 & & \\
\hline Female & 390 & 30 & 323 & 30 & 65 & 31 & & \\
\hline Ethnicity: & 1272 & & & & & & 0.79 & $x^{2}=1.03$ \\
\hline White & 1225 & 96 & 1027 & 97 & 193 & 96 & & \\
\hline Black & 6 & $<1$ & 5 & 1 & 1 & 1 & & \\
\hline Asian & 15 & 1 & 12 & 1 & 2 & 1 & & \\
\hline Mixed & 26 & 2 & 20 & 2 & 6 & 3 & & \\
\hline Highest Level of Education: & 1274 & & & & & & 0.56 & $x^{2}=12.61$ \\
\hline $\begin{array}{l}\text { Masters degree / MBA/ PhD } \\
\text { or equiv }\end{array}$ & 180 & 14 & 154 & 15 & 25 & 12 & & \\
\hline Degree & 380 & 30 & 308 & 29 & 71 & 35 & & \\
\hline $\begin{array}{l}\text { Higher Teaching Qualification } \\
\text { or equiv }\end{array}$ & 127 & 10 & 103 & 10 & 23 & 11 & & \\
\hline A level/SCE Higher or equiv & 166 & 13 & 142 & 13 & 23 & 11 & & \\
\hline $\begin{array}{l}\text { O level/GCSE (Grade A-C) or } \\
\text { equiv }\end{array}$ & 110 & 9 & 92 & 9 & 18 & 9 & & \\
\hline CSE Grade 2-5 / O Levels & 40 & 3 & 29 & 3 & 11 & 5 & & \\
\hline
\end{tabular}




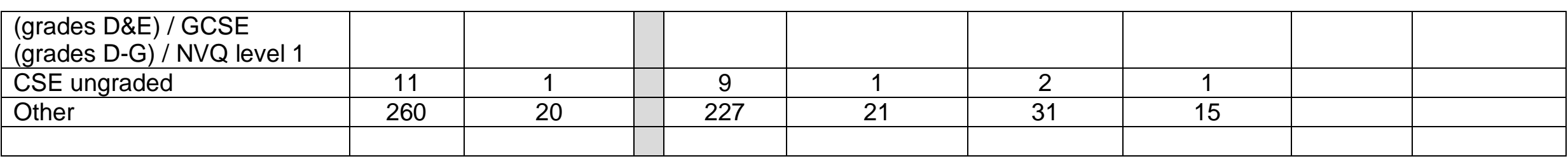


Table 2: E-cigarette patterns of use

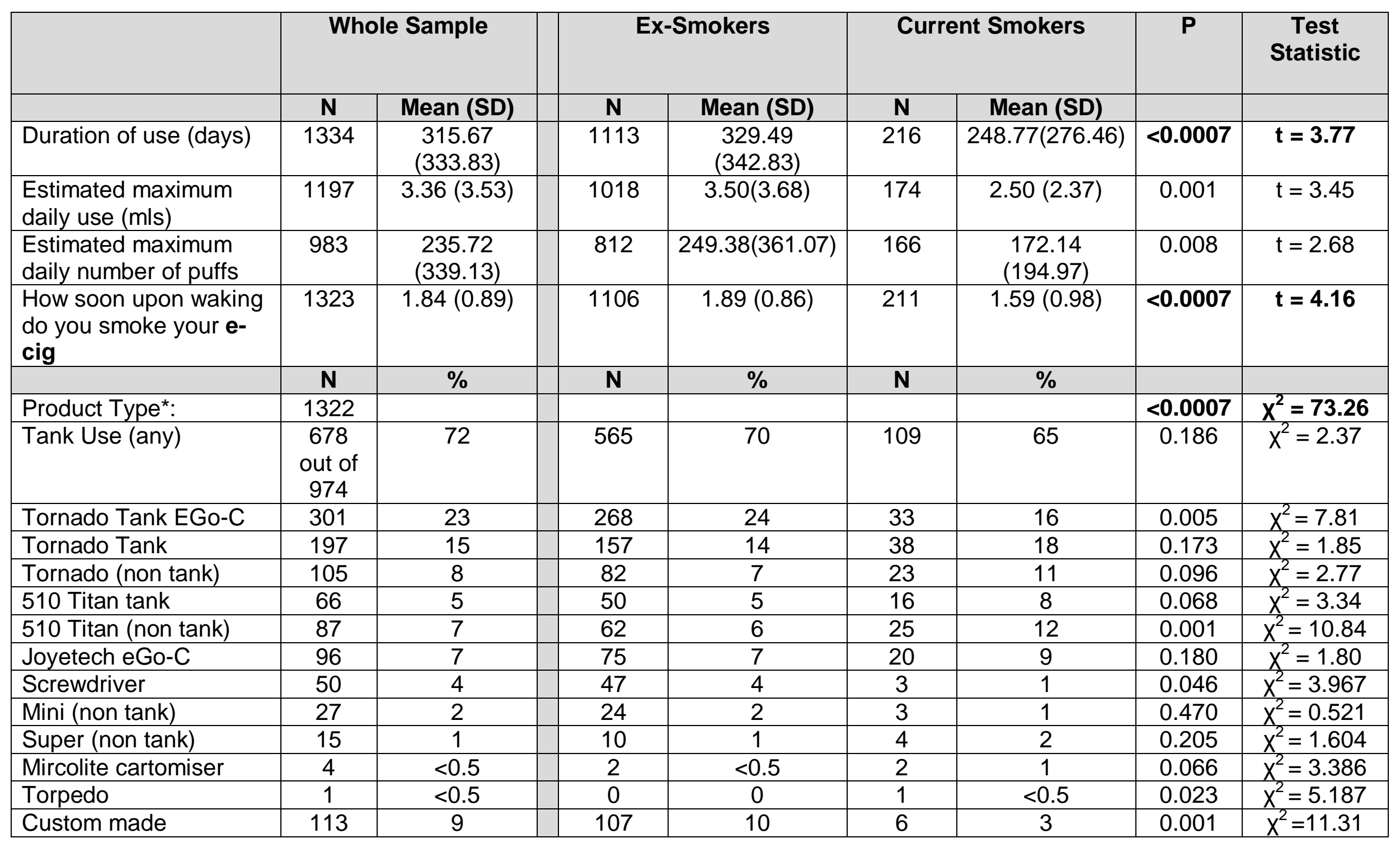




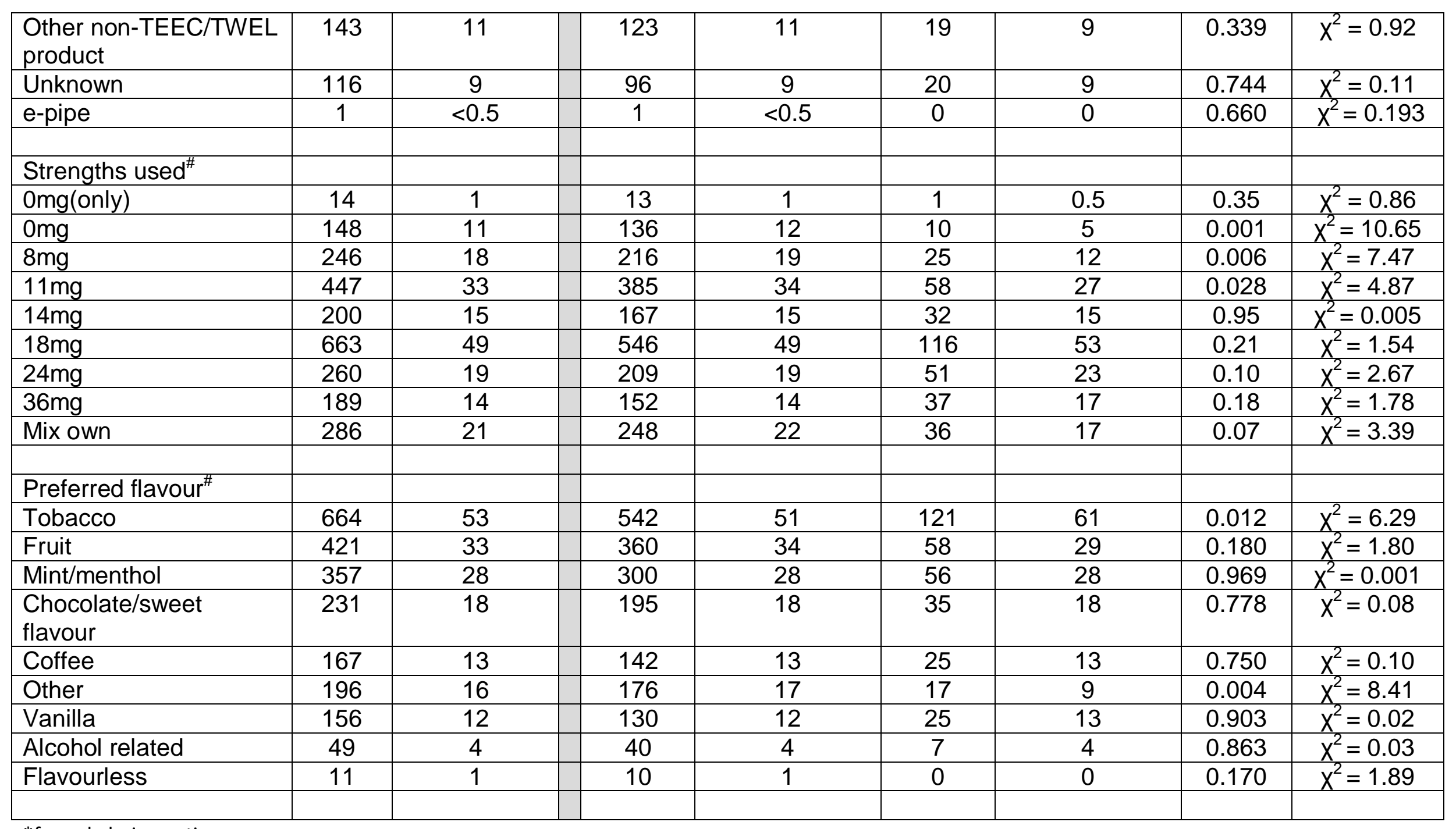

${ }^{*}$ forced-choice options

\# respondents could indicate more than one option 
Table 3: E-cigarette use and effects on tobacco smoking

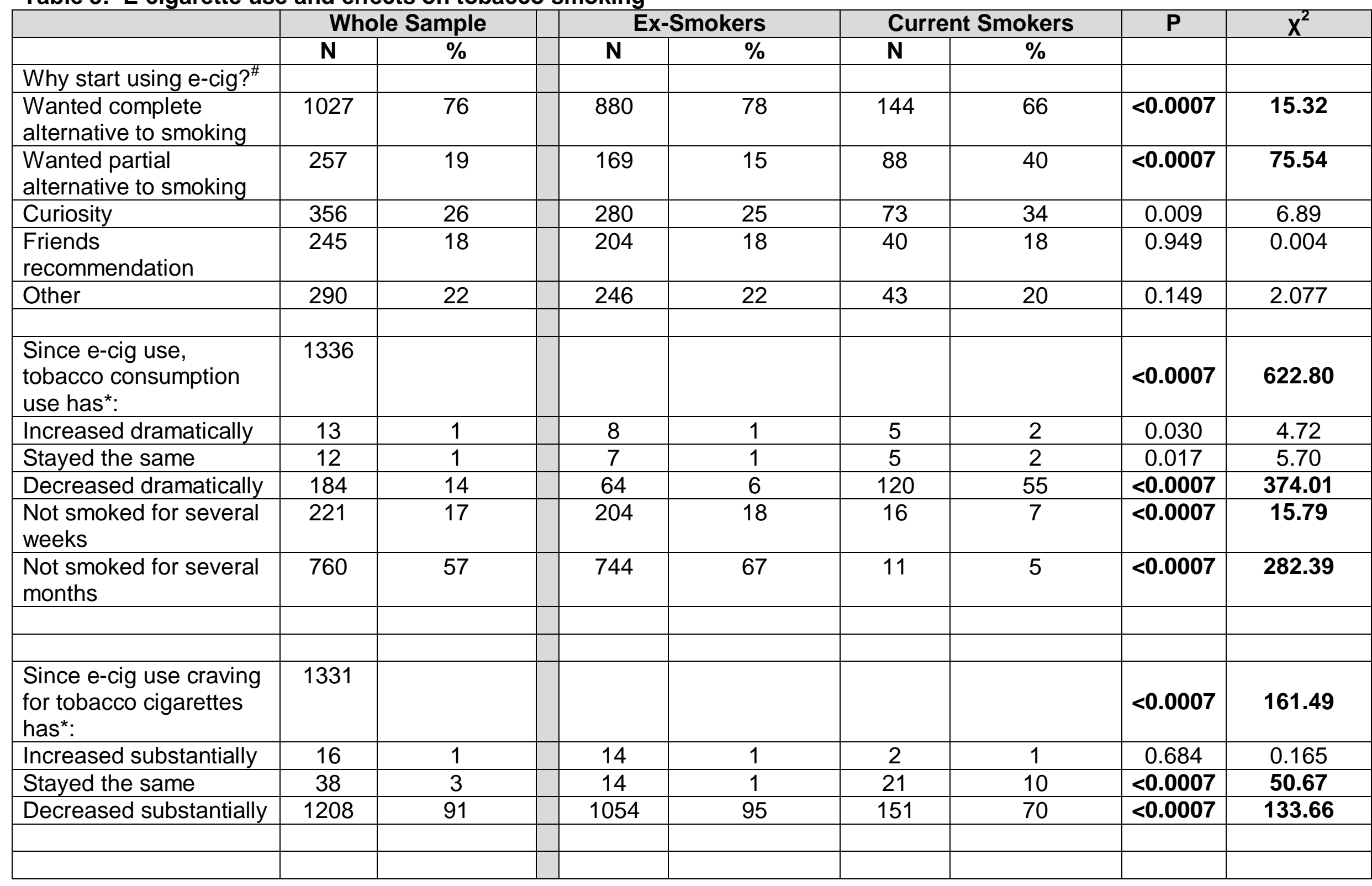




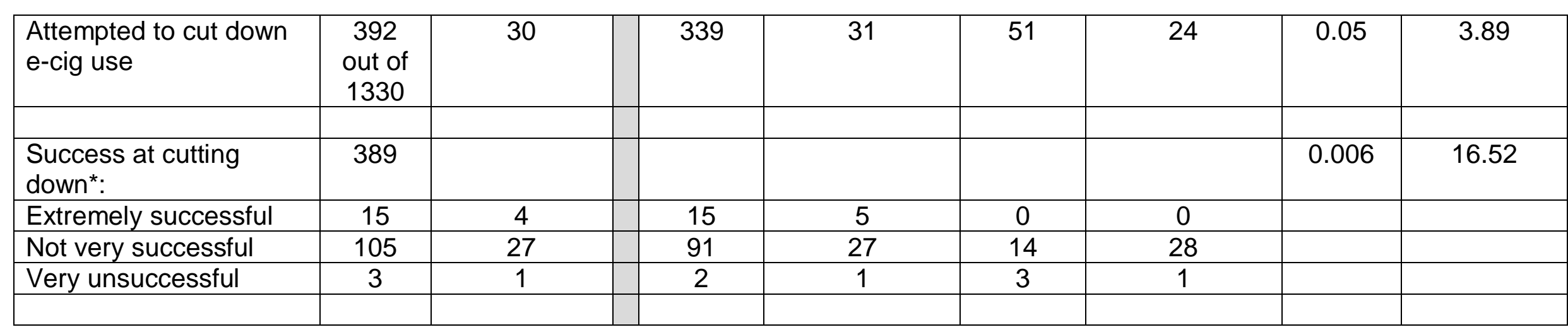

${ }^{*}$ forced-choice options; \# respondents could indicate more than one option 
Table 4: Effects of the Electronic Cigarette (\%)

\begin{tabular}{|c|c|c|c|c|c|c|c|c|c|c|c|}
\hline & \multicolumn{3}{|c|}{ Whole Sample } & \multicolumn{3}{|c|}{ Ex-Smokers } & \multicolumn{3}{|c|}{ Current Smokers } & \multirow[t]{2}{*}{$\mathbf{P}$} & \multirow[t]{2}{*}{$x^{2}$} \\
\hline & $\mathbf{N}$ & Not at all & $\begin{array}{l}\text { Very much } \\
\text { so }\end{array}$ & $\mathbf{N}$ & Not at all & $\begin{array}{c}\text { Very } \\
\text { much So }\end{array}$ & $\mathbf{N}$ & Not at all & $\begin{array}{c}\begin{array}{c}\text { Very } \\
\text { much so }\end{array} \\
\end{array}$ & & \\
\hline $\begin{array}{l}\text { The e-cigarette has helped } \\
\text { me to stop smoking }\end{array}$ & 1333 & 1.5 & 89.4 & 1113 & 0.8 & 97.2 & 216 & 4.2 & 49.5 & $<0.0007$ & 448.09 \\
\hline $\begin{array}{l}\text { My breathing has improved } \\
\text { since using the e-cigarette }\end{array}$ & 1327 & 3.5 & 72.4 & 1109 & 2.4 & 77.5 & 214 & 8.9 & 45.8 & $<0.0007$ & 102.80 \\
\hline $\begin{array}{l}\text { I get a definite nicotine hit } \\
\text { from the e-cigarette }\end{array}$ & 1333 & 3.3 & 56.2 & 1113 & 3.0 & 56.3 & 216 & 5.1 & 56 & 0.100 & 6.28 \\
\hline $\begin{array}{l}\text { I don't like the taste of the } \\
\text { e-cigarette }\end{array}$ & 1330 & 83.2 & 2.6 & 1111 & 84 & 2.7 & 214 & 79.4 & 2.3 & 0.309 & 3.59 \\
\hline $\begin{array}{lll}\text { E-cigarette } & \text { use } & \text { is as } \\
\text { satisfying } & \text { as } & \text { tobacco } \\
\text { smoking } & & \end{array}$ & 1335 & 1.2 & 68.0 & 1115 & 0.9 & 72.4 & 216 & 2.8 & 45.4 & $<0.0007$ & 70.13 \\
\hline $\begin{array}{l}\text { The e-cigarette irritates my } \\
\text { airways more than } \\
\text { cigarettes do/did }\end{array}$ & 1328 & 86.2 & 0.8 & 1107 & 87.3 & 0.8 & 217 & 81.1 & 0.5 & 0.066 & 7.18 \\
\hline $\begin{array}{l}\text { crave e-cigarettes as } \\
\text { much as I do/did tobacco }\end{array}$ & 1322 & 13.3 & 18.4 & 1103 & 12.7 & 18.9 & 215 & 15.3 & 15.8 & 0.421 & 2.82 \\
\hline $\begin{array}{l}\text { l like the e-cigarette } \\
\text { because it looks and feels } \\
\text { like a cigarette }\end{array}$ & 1328 & 40.3 & 17.2 & 1108 & 40.9 & 16.1 & 216 & 36.1 & 23.1 & 0.062 & 7.34 \\
\hline $\begin{array}{l}\text { I sometimes find it } \\
\text { embarrassing using the e- } \\
\text { cigarette in public places }\end{array}$ & 1331 & 45.3 & 6.6 & 1110 & 45.5 & 5.9 & 217 & 45.2 & 10.6 & 0.019 & 9.93 \\
\hline $\begin{array}{l}\text { E-cigarettes feel healthier } \\
\text { than smoking }\end{array}$ & 1325 & 0.5 & 81.4 & 1108 & 0.5 & 83.3 & 213 & 0.9 & 71.8 & $<0.0007$ & 23.62 \\
\hline $\begin{array}{l}\text { The e-cigarette has helped } \\
\text { me to cut down tobacco }\end{array}$ & 1321 & 0.8 & 94.3 & 1107 & 0.5 & 98.3 & 213 & 1.9 & 74.1 & $<0.0007$ & 204.09 \\
\hline
\end{tabular}




\begin{tabular}{|c|c|c|c|c|c|c|c|c|c|c|c|}
\hline smoking & & & & & & & & & & & \\
\hline $\begin{array}{l}\text { enjoy other people's } \\
\text { reactions to me using the } \\
\text { e-cigarette }\end{array}$ & 1330 & 11.7 & 32.2 & 1111 & 11.2 & 32.5 & 214 & 15 & 30.8 & 0.406 & 2.91 \\
\hline $\begin{array}{l}\text { The e-cigarette allows me } \\
\text { to use nicotine more }\end{array}$ & 1327 & 47.6 & 11.1 & 1110 & 48.6 & 10.4 & 213 & 41.8 & 14.6 & 0.020 & 9.82 \\
\hline $\begin{array}{l}\text { My cough has improved } \\
\text { since using the e-cigarette }\end{array}$ & 1310 & 9.0 & 70.3 & 1097 & 8.3 & 75.1 & 209 & 12.4 & 45 & $<0.0007$ & 83.60 \\
\hline $\begin{array}{l}\text { I don't have the urge to } \\
\text { smoke as much since } \\
\text { using the e-cigarette }\end{array}$ & 1319 & 3.8 & 69.7 & 1106 & 3.4 & 73.1 & 209 & 5.7 & 52.2 & $<0.0007$ & 36.49 \\
\hline $\begin{array}{l}\text { The e-cigarette is too } \\
\text { heavy }\end{array}$ & 1324 & 64.3 & 1.4 & 1107 & 65.7 & 1 & 212 & 28.8 & 57.1 & 0.011 & 11.05 \\
\hline $\begin{array}{l}\text { frequently use the e- } \\
\text { cigarette in places where } \\
\text { tobacco smoking is banned }\end{array}$ & 1326 & 16 & 35.9 & 1110 & 15.6 & 35.5 & 211 & 18.5 & 38.4 & 0.368 & 3.16 \\
\hline
\end{tabular}


Table 5: Side effects associated with e-cigarette use (\%)

\begin{tabular}{|c|c|c|c|c|c|c|c|c|c|c|c|}
\hline & \multicolumn{3}{|c|}{ Whole Sample } & \multicolumn{3}{|c|}{ Ex-Smokers } & \multicolumn{3}{|c|}{ Current Smokers } & \multirow[t]{2}{*}{$\mathbf{P}$} & \multirow[t]{2}{*}{$x^{2}$} \\
\hline & $\mathbf{N}$ & Not at all & $\begin{array}{l}\text { All the } \\
\text { time }\end{array}$ & $\mathbf{N}$ & Not at all & $\begin{array}{l}\text { All the } \\
\text { time }\end{array}$ & $\mathbf{N}$ & Not at all & $\begin{array}{l}\text { All the } \\
\text { time }\end{array}$ & & \\
\hline Mouth irritation & 1328 & 76.8 & 0.5 & 1110 & 76.3 & 0.5 & 214 & 79 & 0.5 & 0.714 & 1.36 \\
\hline Throat irritation & 1329 & 63.1 & 0.5 & 1109 & 63.3 & 0.5 & 216 & 62 & 0.5 & 0.018 & 10.10 \\
\hline Aching jaws & 1321 & 94.7 & 0.4 & 1103 & 95.6 & 0.4 & 214 & 90.2 & 0.5 & 0.012 & 11.01 \\
\hline Feeling sick & 1317 & 90.8 & 0.3 & 1101 & 90.9 & 0.4 & 212 & 90.1 & 0 & 0.740 & 1.25 \\
\hline Vomiting & 1307 & 98.8 & 0.3 & 1090 & 98.6 & 0.4 & 213 & 99.5 & 0 & 0.686 & 1.48 \\
\hline Flatulence/Bloating & 1317 & 86.2 & 0.7 & 1103 & 85.6 & 0.7 & 210 & 89 & 0.5 & 0.617 & 1.79 \\
\hline Stomach ache & 1327 & 93.2 & 0.5 & 1106 & 92.7 & 0.5 & 214 & 95.8 & 0.5 & 0.390 & 3.01 \\
\hline Heartburn & 1321 & 85.6 & 0.4 & 1103 & 85.1 & 0.5 & 214 & 87.9 & 0 & 0.200 & 4.65 \\
\hline Diarrhoea & 1318 & 94.3 & 0.2 & 1102 & 94.3 & 0.2 & 212 & 94.3 & 0 & 0.780 & 1.09 \\
\hline Hiccups & 1316 & 89.9 & 0.2 & 1101 & 89.5 & 0.2 & 211 & 91.9 & 0 & 0.518 & 2.27 \\
\hline Feeling dizzy & 1309 & 84.4 & 0.2 & 1100 & 84.5 & 0.2 & 213 & 83.3 & 0.5 & 0.808 & 0.97 \\
\hline Headache & 1309 & 83.7 & 0.2 & 1095 & 83.4 & 0.2 & 210 & 85.1 & 0 & 0.836 & 0.86 \\
\hline Sweatiness & 1317 & 94.1 & 0.3 & 1097 & 94.3 & 0.4 & 208 & 93.4 & 0 & 0.521 & 2.26 \\
\hline Cold hands/feet & 1320 & 96.3 & 0.2 & 1100 & 96.4 & 0.2 & 213 & 95.8 & 0 & 0.663 & 1.58 \\
\hline Palpitations & 1320 & 91.8 & 0.2 & 1104 & 92.1 & 0.2 & 212 & 90.1 & 0.5 & 0.714 & 1.36 \\
\hline
\end{tabular}

